\title{
O perfil socioeconômico dos municípios mineradores paraenses: formação de clusters a partir do IFIRJAN
}

\section{The socioeconomic profile of the municipalities of Pará: miners cluters formation from the IFIRJAN}

Alegria dos Santos Leite - Doutoranda em Desenvolvimento econômico, território e meio ambiente pelo Programa de Pós-Graduação em Economia (PPGE) da Universidade Federal do Pará (UFPA).E-mail: alegria1717@yahoo.com.br

Gisalda Carvalho Filgueiras - Doutora em Ciências Agrárias pela Universidade Federal Rural da Amazônia (UFRA). Professora da Faculdade de Economia da Universidade Federal do Pará (UFPA). E-mail: gisaldaf@yahoo.com.br

Carlos Eduardo Rodrigues Martins - Doutorando em Desenvolvimento econômico, território e meio ambiente pelo Programa de Pós-Graduação em Economia (PPGE) da Universidade Federal do Pará (UFPA). Professor da Faculdade de Economia da UFPA. E-mail: kadumartins91@yahoo.com.br

Suellen Soura Ramos - Doutora em Desenvolvimento Socioambiental pelo Programa de PósGraduação em Desenvolvimento Sustentável do Trópico Úmido do Núcleo de Altos Estudos Amazônicos (NAEA) da Universidade Federal do Pará (UFPA). Economista e Coordenadora de Planejamento na Pró-reitoria de Desenvolvimento Institucional do Instituto Federal do Pará (IFPA). E-mail: suellenramos83@gmail.com

\begin{abstract}
Resumo
$\mathrm{O}$ artigo objetiva analisar o perfil socioeconômico a partir da formação de clusters dos municípios mineradores do estado do Pará. Para tanto, utilizou-se o IFIRJAN2010 nos 31 municípios que apresentaram a atividade mineradora com alguma relevância econômica. Destarte, foram utilizadas técnicas de pesquisa qualitativa e quantitativa por meio de análise estatística multivariada com a finalidade de detectar e identificar agrupamentos similares de municípios em termos econômico-sociais com a finalidade de traçar o perfil da mineração no estado do Pará, uma vez que, em 2013, a mineração respondeu por um terço do PIB do estado e $88 \%$ do valor das exportações. A análise descritiva dos resultados da pesquisa demonstrou índices bastante baixos, o que aponta para uma pequena importância da atividade mineral na elevação dos pesos dos subíndices do IFIRJAN atribuída aos aspectos referentes ao emprego e renda, educação e saúde. A análise de cluster permitiu a classificação dos municípios mineradores em três grupos, sendo que o maior deles, com 39\% dos municípios apresentaram os melhores resultados nos subíndices do IFIRJAN (embora não proporcionais à dimensão econômica da mineração neste aglomerado), bem como PIB, taxa de desflorestamento e vínculos empregatícios. Ademais, os outros dois clusters apresentaram atividades ainda incipientes e com fases iniciais de exploração mineral.
\end{abstract}

\section{Palavras-chave}

Mineração. Cluster. IFIRJAN. Pará.

\begin{abstract}
The study aimed to analyze the socioeconomic profile from the formation of clusters of mining cities of state of Pará. For this, was used the IFIRJAN-2010 in thirty-one counties that submit mining activity with some economic relevance. Thus, was used techniques of qualitative and quantitative research through multivariate statistical analysis in order to detect and identify similar groupings of municipalities in economic and social terms to define the profile of mining in Pará. Since in 2013, mining accounted for a third of the state's GDP and $88 \%$ of export value. The descriptive analysis of the survey results shows very low levels, pointing to a small amount of mineral activity in elevating the weights assigned to IFIRJAN aspects relating to employment and income, education and health. Cluster analysis allowed the classification of mining cities in three groups, with the largest, with $39 \%$ of the municipalities has the best record in the subletter IFIRJAN as well as GDP, rate of deforestation and employments, the other two clusters have activities yet early stages of exploration.
\end{abstract}

\section{Keywords}

Mining. Cluster. IFIRJAN. Pará. 


\section{INTRODUÇÃO}

O Banco Mundial considera a existência de economia mineira em um país, território ou região cujo setor mineral represente mais de $10 \%$ do seu Produto Interno Bruto (PIB) e contribua com mais de 50\% das suas exportações, que é o caso do estado do Pará. Além disso, para se tornar uma economia mineral, a região deve apresentar dimensões de depósitos consideráveis e atrativos, que nada mais são do que jazidas e minas, dados que são condicionantes para que os agentes econômicos de grande e pequeno porte possam investir e explorar esta atividade.

A atividade mineral é representada por três setores da economia: primário, que engloba a pesquisa mineral e mineração; secundário (de transformação mineral, que envolve a metalurgia, siderurgia e química) e a terciária (mercado e comércio). Por esta visão, dada a amplitude de abrangência setorial, percebe-se que a atividade mineral pode desempenhar importante papel no desenvolvimento econômico e social de uma sociedade, região ou país.

A mineração no Brasil encontra-se em posição de destaque dado ao ambiente de geodiversidade que condiciona vantagens comparativas das jazidas de classe internacional, associadas às províncias minerais e que asseguram as vantagens competitivas ao negócio mineral do Brasil. Podem ser citadas as jazidas: "Polimetálica de Carajás", "Manganesífera da Serra do Navio", "Polimetálica do Mapuera", "Estanífera de Rondônia", "Aurodiamantífera Roosevelt Aripuanã”, "Auríferas do Alto Guaporé", “de Alta Floresta” e "do Tapajós”; "Quadrilátero Ferrífero" etc.

Outro fator a destacar é o posicionamento do Brasil definitivamente na rota dos fluxos financeiros, tornando-se um dos principais alvos para os investidores estrangeiros, conforme cenários de mercado otimistas projetados sobre o ingresso de Investimento Estrangeiro Direto (IED) no país de 2010 2013, pois a média de investimentos ficou em torno de $\mathrm{R} \$ 35$ bilhões de dólares (BNDES, 2009).

Segundo Ministério de Minas e Energia (MME, 2009), a produção mineral no Brasil tem como origem 3.354 minas legalizadas. Destas, 159 são de grande porte (minas que apresentam um milhão de toneladas/ano- run of mine, 5\% do total), 837 de médio porte (abaixo de milhão de toneladas/ ano e acima de 100 mil toneladas / ano de run of mine $24 \%$ do total), e 2.358 minas de pequeno porte (abaixo de 100 mil toneladas/ano e acima de 10 mil toneladas/ano run of mine), $71 \%$ do total. Destaca-se ainda que o país possui grandes reservas de nióbio, tantaliza, grafite, bauxita, caulim, ferro e estanho. 
Na Amazônia legal, a importância da mineração data dos anos de 1970, com a implantação de grandes projetos para desenvolver e integrar esta região junto ao país e ao resto do mundo. Um estudo completo que trata deste período e da questão da mineração na Amazônia Legal foi elaborado pelo Centro de Tecnologia Mineral (CETEM), denominado "O Banco de Dados SUSTEMIN - Sustentabilidade da Mineração na Amazônia”, sendo uma referência de estudos feitos na época para se discutir o impacto da mineração na Amazônia (BARCELLOS; LIMA, 2002). Naquele período, a participação dos principais minerais em relação ao Brasil foi revelado, indicando a magnitude na participação de minérios para o Brasil e mundo, sendo que o estado do Pará se destaca com maior número de reservas e de atividades voltadas para o setor mineral, conforme será analisado mais à frente.

Em termos mais específicos, o estado do Pará, em menos de sete décadas, tornou-se o segundo maior produtor mineral do Brasil, ficando atrás somente de Minas Gerais que já desenvolve a mineração há mais de três séculos. Dos 15,8 bilhões de dólares em exportações totais do Pará, no ano de 2013, 88\% deste valor se deve à indústria de mineração e transformação mineral, fazendo do setor mineral o carro chefe das exportações paraenses, sendo que o ferro corresponde no total de participações a 70,7\% das exportações, além do cobre $(9,6 \%)$, da alumina calcinada $(7,1 \%)$, da bauxita $(1,7 \%)$, do caulim $(1,6 \%)$ e do manganês $(1,5 \%)$, os principais produtos minerais exportados. Os três principais mercados compradores dos bens minerais do Pará foram a China (56 milhões de toneladas), o Japão (13 milhões de toneladas) e a Alemanha (7,9 milhões de toneladas), segundo dados do Ministério de Desenvolvimento da Indústria e Comércio (MDIC, 2013). Segundo o Sindicato das Indústrias Minerais do Pará (SIMINERAL, 2013), a cadeia mineral respondeu por 271 mil empregos diretos e indiretos no ano de 2013. Segundo o relatório desta instituição, para cada emprego direto gerado na indústria mineral, criam-se outros treze postos de trabalho ao longo da cadeia produtiva. A arrecadação do royalty da CFEM aumentou em um ano, de 2012 para 2013, 53\% sendo Parauapebas e Canaã dos Carajás os dois municípios com o maior volume de arrecadação.

Neste cenário, busca-se apresentar, tendo em mente as análises teóricas do desenvolvimento, a importância da atividade mineradora para os municípios do estado do Pará, na medida em que analisa em forma de aglomeração 31 municípios que realizam a referida atividade. Foram utilizados dados quantitativos, a partir do índice FIRJAN, para demonstrar a realidade econômica e social do município, apontando a importância econômica da atividade como principal geradora de externalidades. 
A metodologia utilizada neste trabalho é qualitativa na medida em que se utiliza de pesquisas históricas, teórica e social, buscando respostas em um grupo social, por meio do uso de fontes formais via pesquisa bibliográfica e historiográfica. Também se trata de um artigo que usa dados quantitativos, utilizando-se de dados institucionais como o Índice da Federação das Indústrias do Rio de Janeiro (IFIRJAN), expressando-se por meio da análise de cluster que teve como finalidade a classificação e o agrupamento de municípios em função de sua similaridade frente ao IFIRJAN emprego e renda, educação e saúde. Portanto, por essas similaridades, pode-se por meio de políticas públicas intervir nos territórios ações que possam alavancar o desenvolvimento local e regional.

Desta forma, além deste proêmio, o artigo encontra-se dividido no seguinte formato: (ii) revisão teórica, (iii) metodologia (iv )resultados e discussão (v) conclusão.

\section{REVISÃO TEÓRICA}

A literatura sobre o desenvolvimento socioeconômico em municípios detentores de reservas minerais converge no sentido de compreender a atual dinâmica de exploração dos minérios e atividades congêneres na Amazônia a partir das primeiras iniciativas capitaneadas pelo Estado autoritário nas décadas de 1960 e 1970. Tais iniciativas tinham por objetivo a ocupação dos espaços vazios, conforme o ideário da Doutrina de Segurança Nacional, acrescentado à necessidade de obtenção de divisas para financiar o crescente déficit da balança comercial brasileira (tendo em vista o processo de deterioração das contas externas nacionais a partir do fim do milagre na segunda metade da década de 1970) por meio das exportações dos minérios em grande escala para os países industrializados centrais.

Por meio da conjunção Estado e capital internacional, potencializada por reformas de cunho jurídico que viessem ao encontro das aspirações dos grandes conglomerados na região, tal qual o novo Código de Minas, de 1967, o caminho foi propício para a instalação de grandes projetos de exploração das riquezas minerais amazônicas, de reduzido proveito para a realidade das sociedades locais e regidos sob a lógica inexorável do grande capital. Carvalho (2006, p. 2) ressalta que se esperava que os "grandes Projetos Minerais pudessem originar outras atividades produtivas capazes de contribuir à promoção do desenvolvimento da Amazônia Legal como preconizava a estratégia de desenvolvimento regional do II Plano Nacional de Desenvolvimento (II PND)". 
Acreditava-se que os projetos industriais de mineração pudessem alavancar e produzir verdadeiros polos de desenvolvimento advindos da industrialização de produtos minerais. Carvalho (2001) atenta para o fato de que a estratégia de desenvolvimento da Amazônia levava a crer que, após a criação dos polos extrativos minerais, estes atrairiam novos investidores capazes de desenvolverem os polos siderúrgicos e metalúrgicos que, por sua vez, iriam atrair novas indústrias processadoras de base e de transformação num nítido processo de industrialização gerando efeitos de linkages. "Além dos efeitos para trás, esperavase que o processo de industrialização desencadeasse os seus efeitos em cadeia para frente de forma a atrair as modernas indústrias eletrolíticas e eletrotérmicas vorazes consumidoras de energia elétrica das grandes hidrelétricas da Amazônia" (COSTA, 1987, p. 39-40).

A mineração tornou-se uma das atividades de maior destaque no Pará - sendo este o segundo maior estado minerador do Brasil e primeiro em extração de ferro. No estado do Pará, principal lócus mineiro da Amazônia, o setor mineral responde por 88\% das exportações (MDIC, 2013) e um terço do Produto Interno Bruto (PIB) estadual (IBGE, 2013). No ano de 2011, o estado do Pará obteve uma quantidade produzida de minérios na ordem de 448.582.303 toneladas, segundo do Departamento Nacional de Produção Mineral (DNPM).

De acordo com o Anuário Mineral do Pará (2012), a atividade está presente em 32 municípios paraenses, divididos em três níveis da cadeia produtiva (pesquisa mineral, extração mineral e transformação mineral). Tal atividade é acompanhada por mudanças socioeconômicas e ambientais nas localidades na qual são implantadas, no entanto, há uma grande discussão acadêmica sobre a capacidade de esta atividade impulsionar o desenvolvimento econômico e social nos municípios em que estão instaladas.

Isto porque, ao longo de quase 50 anos de extração e industrialização mineral na Amazônia, com destaque para o estado do Pará, vários autores já confirmaram esta indústria como um grande enclave econômico. Implica dizer que os benefícios relacionados ao social e ambiental tem sido mínimos.

Nesse contexto, Enriquez (1998) ressalta que apesar de a Amazônia brasileira possuir uma das maiores e mais diversificadas reservas minerais do planeta e altos valores da produção, o setor mineral não tem sido um vetor de desenvolvimento regional. O setor mineral emprega apenas $0,45 \%$ da mão-deobra economicamente ativa da Amazônia, contribui com menos de 4\% das arrecadações de impostos e seus efeitos multiplicadores em outros setores da economia regional são ínfimos (VIDAL; SANTANA, 1998). Essa incapacidade de gerar benefícios para a sociedade local no presente e no futuro é ainda mais 
preocupante devido ao fato de os minérios serem um recurso não renovável, diminuindo o estoque de capital para o futuro.

Monteiro et al. (2008) - estudando o distrito industrial de Barcarena, no estado do Pará e as quatro grandes empresas mínero-metalúrgicas no entorno da Albras, uma empresa que produz alumínio primário; da Alunorte, uma empresa que produz alumina (insumo para a produção do alumínio primário); e de duas outras empresas responsáveis pela extração, beneficiamento e comercialização de caulim com a rede de empresas fornecedoras de insumos e prestadoras de serviços que atuam no aglomerado local - destacam que houve grandes limitações à ampliação da verticalização da produção industrial de mercadorias geradas a partir da transformação industrial primária de bens minerais em Barcarena e que as relações institucionais entre as quatro empresas mineradoras e as prestadoras de serviços não foram tão satisfatórias para a sociedade local, uma vez que as dinâmicas engendradas não foram tão intensas, sendo marcadas pela baixa cooperação entre as empresas "motrizes" e subcontratadas e com instituições de ensino e pesquisa.

Enriquez (1998), analisando o impacto da Compensação Financeira pela Exploração Mineral (CFEM), uma espécie de royalty imposta no início dos anos de 1990 no Brasil com o objetivo de capturar parte do valor da renda referente à diminuição do estoque mineral nos municípios mineradores de Parauapebas e Oriximiná, no estado do Pará, conclui que ainda se necessita de mudanças na tributação, fiscalização e utilização dos royalties com a finalidade de tornar o setor mineral um genuíno vetor de desenvolvimento regional e de assegurar que as gerações presentes e futuras se beneficiem da exploração dos estoques minerais.

Nesta direção, a discussão que se tem levado em nível acadêmico e institucional é o quanto a economia mineradora pode contribuir com o desenvolvimento endógeno regional e o quanto sua exploração deve ser sustentável, de modo a minimizar seus impactos ambientais. Tanto assim que estudos relativos de alguns autores, como Monteiro (2005), Vieira (2011), Deus e Nascimento (s/d), tem constatado a grande dificuldade para que a exploração de minerais cumpram esse processo básico de qualquer extração de recurso natural, qual seja, ser sustentável nas três dimensões básicas: econômico, social e ambiental. Isto porque, na visão de Monteiro (2005), na Amazônia, após meio século de mineração, com destaque para o estado do Pará, com a implementação do PGC,

as indústrias mínero-metalúrgicas tiveram enormes limitações em impulsionar dinâmicas de desenvolvimento amplas e socialmente enraizadas, o que resulta, em grande medida, das trajetórias e dinâmicas de inovação tecnológica a que são vinculadas, da ambiência institucional 
na qual estão inseridas e da pouca importância que é requerida das especificidades sociais, culturais e ecológicas locais para garantir a competitividade da valorização pouco qualificada de recursos minerais da região (p. 206).

Entretanto, na contramão da maioria dos autores que enxergam grande negatividade na mineração na Amazônia, Oliveira (2016, n.p) questiona: "Se há tantas necessidades e benefícios suportados pela mineração, por que sua imagem coletiva é tão ruim?”. Este autor aponta exemplos bons da mineração e sustentabilidade ambiental, social e econômica, que ocorre com a produção de óleo e gás em Urucu, que, segundo ele, “com mínimo impacto sobre a floresta e grande efeito positivo na economia do município de Coari e do estado do Amazonas" (OLIVEIRA, 2016, n.p). Outro exemplo de parâmetros sustentável é mostrado ainda por Oliveira (2016), no caso de Carajás. Segundo este autor: “o PGC conteve o desmatamento na região e promoveu a economia dos municípios e estados do Pará e Maranhão, que orbitam ao redor do complexo mina-ferroviaporto" (OLIVEIRA, 2016, n.p)

$\mathrm{Na}$ mesma linha de pensamento, outros autores também refutam a vinculação da mineração à ausência de desenvolvimento econômico. Por exemplo, de acordo com Radetzki (1992) apud Rodrigues (2009), as economias subdesenvolvidas devem aproveitar e extrair o quanto antes suas riquezas minerais, pois a mineração exerce um importante papel no progresso tecnológico, rejeitando a alternativa de conservar tais recursos para as futuras gerações.

Na sequência, Enriquez (2009) adiciona um parecer favorável na questão da sustentabilidade da mineração, pois, em um levantamento empírico em 15 grandes municípios mineradores do Brasil, abrangendo oito estados brasileiros (Amapá, Bahia, Goiás, Mato Grosso do Sul, Minas Gerais, Pará, Santa Catarina e Sergipe), comparou a trajetória ambiental desses municípios com seus entornos não mineradores, a partir de dados de indicadores secundários e conclui que, ao contrário do que se propala, “os municípios de base mineradora têm um forte sistema de proteção ambiental, uma vez que a dimensão ecológica está razoavelmente institucionalizada em torno de marcos regulatórios e órgãos especialmente voltados para o trato da questão ambiental" (ENRIQUEZ, 2009, p. 51). O autor confirma também a questão da ausência de um padrão homogêneo para tratar da sustentabilidade da mineração nos referidos municípios, o que acaba por acarretar um viés regional. Nesse aspecto, faz-se necessário que o capital humano e a governança fiquem mais presentes e atuem conjuntamente e de forma compartilhada. 
Dito de outra forma, nas palavras de Oliveira (2016, n.p), "o setor mineral, composto de prospectores, empresas de bens e serviços, entes federados e comunidades afetadas, é importante para o país, pode gerar o desenvolvimento regional, com pouco impacto ambiental, mas deve avançar no sentido de partilhar seus recursos".

Implica dizer, no caso específico da Amazônia, que o recurso arrecadado pela CFEM, conforme aquele autor, tem contribuído para uma concentração de renda para o município (65\%), dado que inexiste uma vinculação com políticas públicas e, para tanto, faz-se necessário uma mudança que leve sim à alavancagem de atividades sustentáveis e estruturantes, tais como a educação e o meio ambiente.

Outrossim, não é objetivo deste artigo discutir a mineração enquanto atividade de impactos negativos na economia e no meio ambiente, mas sim, ser uma contribuição em nível de descortinar os perfis dos municípios mineradores paraenses, de modo a auxiliar na formulação de políticas públicas que acabem por retomar a discussão para que esta atividade venha, em um futuro próprio, a se desenvolver de forma endógena, espraiando seus benefícios econômicos, sociais e ambientais para a sociedade regional e quiçá, para o resto do país.

\section{METODOLOGIA}

\subsection{UNIVERSO E AMOSTRA DA PESQUISA}

Dos 143 municípios paraenses, a atividade minerária, segundo o anuário mineral, está presente em 32, nos três processos da mineração. Nesta pesquisa, optou-se por realizar um censo, por meio da coleta de dados incluindo todos os indivíduos (municípios) integrantes deste universo. Dos 32 municípios, apenas o município de Cachoeira do Piriá foi desconsiderado, por apresentar a atividade ainda em fase de pesquisa mineral, não apresentar IFIRJAN 2010 e os dados institucionais serem escassos quando analisados para a atividade mineral. Por meio dos subíndices do Índice de Firjan de Desenvolvimento Municipal (IFDM) efetuou-se a análise de cluster.

A análise da variável IFIRJAN compreendeu o período de 2000 a 2010, portanto, 11 anos. Este índice é decomposto, como sublinhado anteriormente, em três variáveis (emprego-renda, educação e saúde) que medem o grau de desenvolvimento municipal (IFDM) e varia de 0 a 1 e, como o IDH, quanto mais próximo de um, melhor o desenvolvimento local do(s) município(s) em análise, o que permite analisar a trajetória do crescimento sustentável localmente, podendo, inclusive, melhorar, por intermédio de ações propulsoras de políticas regionais, a performance dos municípios em análise. 
Ademais, usou-se conjuntamente outras variáveis em uma estatística descritiva para confirmar mais adiante os resultados de agrupamentos em cluster, que em nível de técnica de análise multivariada é bastante empregada para diversos fins. No entanto, para o Pará e na atividade mineradora ainda não se conhece a sua aplicação, o que torna este trabalho inovador, neste momento, o seu uso comparativamente a muitos outros trabalhos realizados, com métodos qualitativos, descritivos, políticos, sociológicos e até com emprego de instrumentos algébricos como a Matriz de Insumo Produto e Matriz de Contabilidade Social, para mensurar o impacto do setor mineral.

\subsection{MODELO EMPÍRICO (ANÁLISE DE CLUSTER)}

Para Hair et al. (2006), a análise de cluster é tida como um conjunto de técnicas multivariadas, o qual tem por finalidade a classificação e o agrupamento de indivíduos em função de sua similaridade frente a um determinado fator ou conjunto de fatores. Assim, torna-se similar à análise fatorial no sentido de ser uma técnica multivariada de dados, entretanto se difere desta porque busca agregar objetos (municípios, regiões, empresas etc.) com base na similaridade deles, ao invés de agregar variáveis comuns como ocorre na análise fatorial (FILGUERAS et al., 2013).

Neste estudo, foi utilizado procedimento hierárquico do tipo aglomerativo, em que os elementos, tomados separadamente, são progressivamente combinados, em função de sua similaridade, de forma a construir novos agrupamentos, até que se obtenha um único agrupamento - representado graficamente por meio de um dendograma (HAIR et al., 2006).

Mais precisamente, a análise de cluster pode ser colocada da seguinte maneira (CARVALHO; SANTANA; MENDES, 2006 apud FILGUERAS et al., 2013):

Seja $\mathrm{X}=\{\mathrm{X} 1, \mathrm{X} 2, \ldots, \mathrm{Xn}\}$ um conjunto de variáveis

$\mathrm{E}=\{\mathrm{E} 1, \mathrm{E} 2, \ldots . . \mathrm{En}\}$ o conjunto de objetos que se deseja agrupar

Com base no conjunto $\mathbf{X}$, pode-se determinar uma partição de $\mathbf{E}$ em grupos $\mathbf{G n}$ de maneira que:

\footnotetext{
Se Er, Es $\varepsilon$ Gi $\rightarrow$ São semelhantes

Se $\operatorname{Er} \varepsilon$ Gi, Es $\varepsilon$ Gi $\rightarrow$ São dessemelhantes
} 
Para solucionar este problema, definiu-se uma medida de similaridade entre os objetos analisados. Para tanto, por se tratar de dados métricos, escolheuse a utilização de medidas de distância como medida de similaridade. Segundo Filgueras et al. (2013), entre as medidas de distância para similaridade, as mais usadas são: a distância euclideana, a distância euclediana (com i ou com e?) quadrada e a city-block.

Utilizou-se a distância euclediana, que consiste na mensuração de um segmento de reta desenhado entre dois objetos, tal que dadas duas variáveis $\mathrm{X}$ e $\mathrm{Y}$ que podem ser representadas num espaço bidimensional por pontos cujas coordenadas sejam (X1, Y1) e (X2, Y2), tem-se:

$$
D=\sqrt{(\mathrm{X} 2-\mathrm{X} 1)-(\mathrm{Y} 2-\mathrm{Y} 1)_{2}}
$$

Nesta pesquisa se utilizou o método de Ward, calculado a partir da medida de dissimilaridade da distância euclidiana até o quadrado entre dois elementos (i e k), representado pela expressão (MINGOTE, 2005):

$$
\mathrm{d}^{2}=\sum_{\mathrm{k}=1}^{\mathrm{p}}\left(\mathrm{x}_{\mathrm{k}}-\mathrm{x}_{\mathrm{i}}\right)^{2}
$$

Onde dij $^{2}$ representa a j-ésima característica do i-ésimo indivíduo; xik representa a j- ésima característica do i-ésimo indivíduo; e, xik' representa a j-ésima característica do i'-esimo indivíduo.

\section{RESULTADOS E DISCUSSÃO}

A análise descritiva dos resultados da pesquisa demonstra índices bastante baixos, o que aponta para uma pequena importância da atividade mineral na elevação dos pesos dos IFIRJAN, atribuída aos aspectos referentes a emprego e renda, educação e saúde (Tabela 1).

Tabela 1 - Análise descritiva dos IFIRJAN, no período de 2000 a 2010

\begin{tabular}{l|c|c|c}
\hline & $\begin{array}{c}\text { FIRJAN Emprego e } \\
\text { Renda }\end{array}$ & $\begin{array}{c}\text { FIRJAN } \\
\text { Educação }\end{array}$ & $\begin{array}{c}\text { FIRJAN } \\
\text { Saúde }\end{array}$ \\
\hline Total & $\mathbf{1 4 , 9 1}$ & $\mathbf{1 8 , 7 7}$ & $\mathbf{2 0 , 6 2}$ \\
\hline Média & 0,48 & 0,61 & 0,67 \\
\hline Desvio padrão & 0,16 & 0,06 & 0,07 \\
\hline Coeficiente de variação & 33,77 & 10,26 & 10,75 \\
\hline
\end{tabular}

Fonte: Resultados da pesquisa, 2014. 
Considerando-se a importância dos aspectos aqui levantados para a possibilidade de indução do desenvolvimento regional a partir dos índices, ora em estudo, a análise descritiva aponta para uma reduzida capacidade de promoção do desenvolvimento a partir da atividade mineradora, pois todos os resultados são pouco satisfatórios, particularmente os indicadores relacionados à dimensão emprego e renda. Este resultado corrobora a afirmação de Enriquez (1998), que ressalta a incapacidade da mineração gerar, na Amazônia, benefícios explícitos para a sociedade local, principalmente quando se refere à endogenia da rendas minerais, conforme dito acima, apesar de ter um crescimento elevado na sua produção. Para se ter uma ideia, os 31 municípios ora estudados, representam juntos 43\% do PIB do estado (IBGE, 2012), a taxa de crescimento do valor exportado na indústria mineral (indústria de transformação e indústria extrativa) do estado do Pará, da década de 1990 a 2012 cresceu 1.033\%, com o visto no Gráfico 1.

Gráfico 1 - Exportações dos produtos da indústria minero-metalúrgica do Pará, 1990-2012. Em US\$ FOB

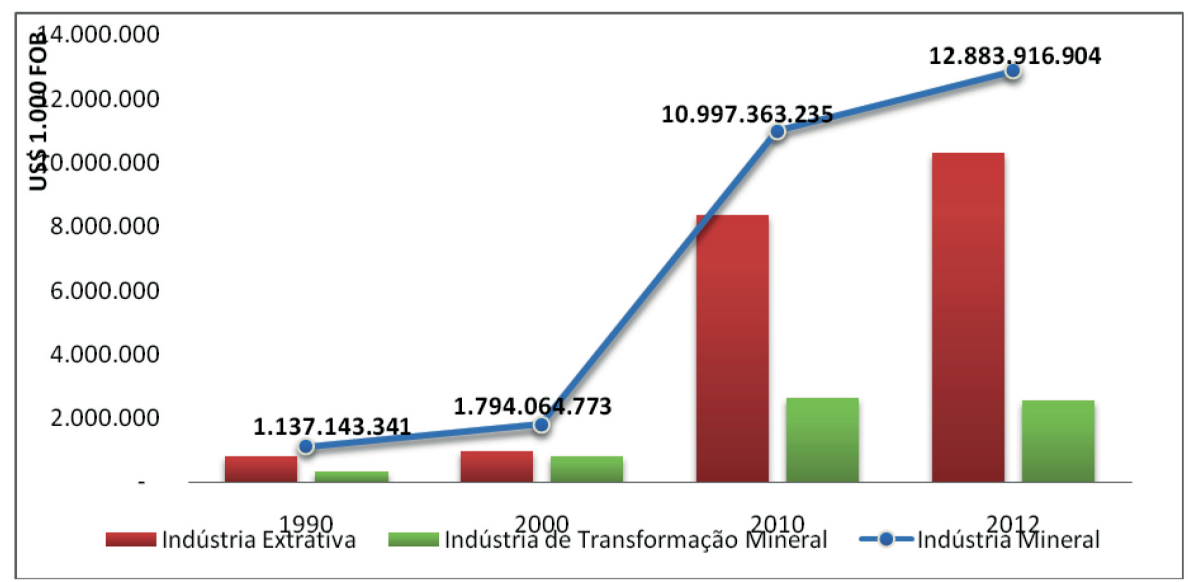

Fonte: MDIC (2012).

Quando se analisa a evolução do emprego da atividade em epígrafe, percebe-se que há uma evolução na geração de empregos, todavia, esta não acompanha a proporção do salto crescente do setor e seu consequente aumento das exportações, como se vê no Gráfico 2.

A indústria de extração mineral metálica foi a que mais cresceu no estado, chegando, em 2013, a empregar mais de 12 mil profissionais diretamente, ao passo que a de não metálicos empregou 1.686. 
Gráfico 2 - Evolução do emprego na extração de minerais metálicos e minerais não metálicos no estado do Pará, 2002 - 2011

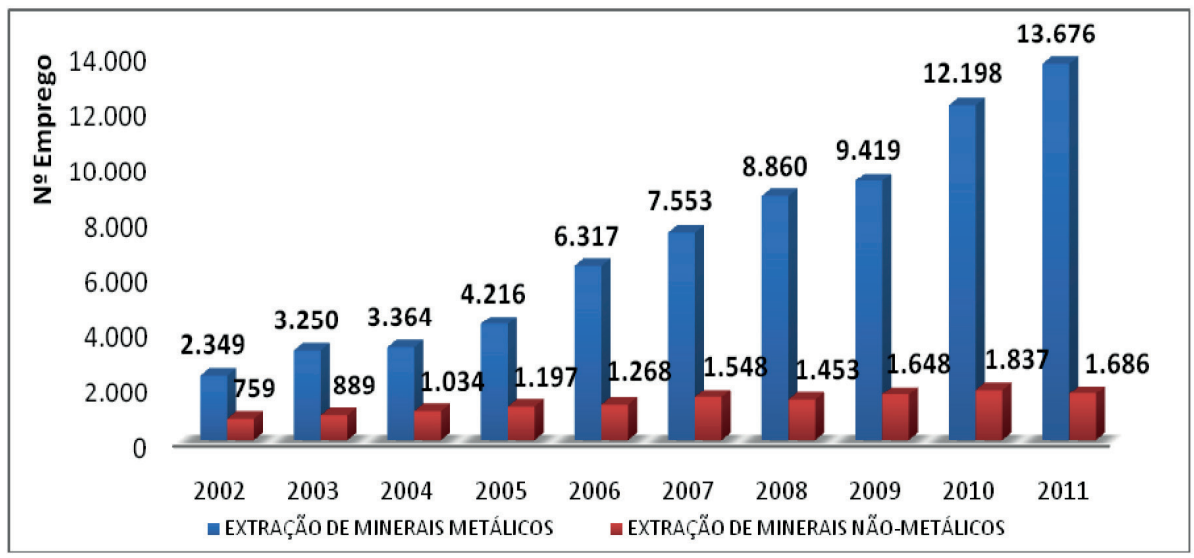

Fonte: MTE/RAIS (2012).

A análise de cluster realiza o agrupamento dos indivíduos de acordo com seu padrão de comportamento em relação a um determinado fator de influência, no caso, os escores fatoriais. Desta maneira, pretende-se reunir os municípios que apresentam a mineração em grupos, ou clusters, que apresentam comportamento similar em relação ao seu próprio grupo, e dessemelhante quando comparado com os integrantes dos demais grupos.

O número ideal de clusters foi definido por meio da chamada "Regra de Parada", que consiste na análise dos coeficientes de variação entre as etapas do processo de composição dos grupos. Quando há uma variação considerada anormal ou irregular em relação ao padrão de variação observado, deve-se considerar como indicada a etapa imediatamente anterior.

Após a aplicação de procedimento para a determinação do número de clusters, verificou-se que os indivíduos foram agrupados em três diferentes conjuntos, sendo que o cluster 1 reuniu nove (9) municípios, equivalentes a 29\% do total da amostra; o cluster 2 apresentou a maior quantidade de municípios (12), representando 39\% dos municípios estudados; o cluster 3 foi composto por 10 municípios, equivalentes a $32 \%$ do total de municípios que integraram a amostra do estudo (Gráfico 3). 
Gráfico 3 - Composição dos Clusters formados, de 2000 a 2014

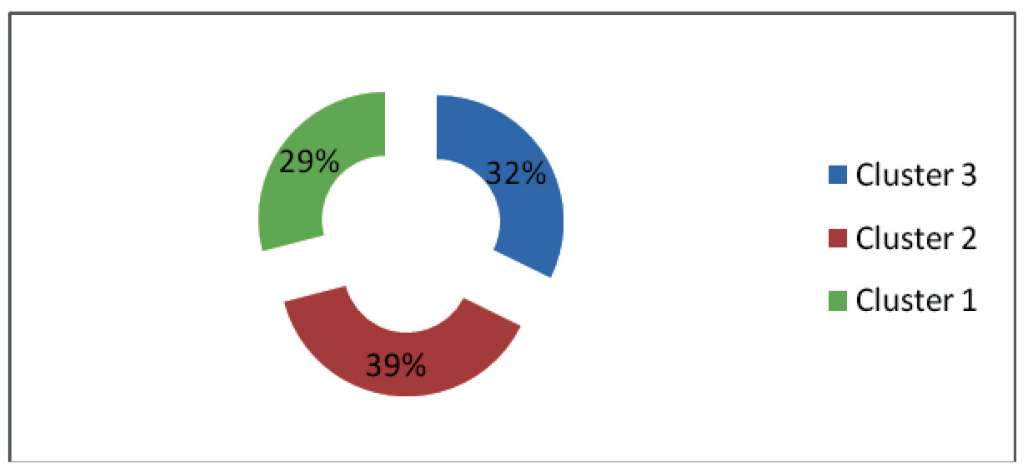

Fonte: Resultados da pesquisa, 2014.

O cluster 1 congrega os municípios que ainda estão em fases iniciais da atividade mineradora, tais como a pesquisa e a autorização de exploração do minério, bem como a implantação de plantas industriais, como a de São Felix do Xingu para exploração de níquel; a de exploração do ouro, em Cumaru do Norte; e a de bauxita, em Alenquer. Também congregam a produção de minerais de pouca quantidade vendida e baixo valor como sal marinho e cimento. Mencionam-se também as grandes empresas, como a Ymeris, que tem minas de Caulim em Ipixuna do Pará, as quais ainda estão em fase de expansão da capacidade produtiva.

Ressalta-se que o cluster 2 é formado pelas maiores economias mineiras do estado. O somatório do PIB de seus municípios é 13 vezes maior que o PIB total dos clusters 3 e 1.

Os municípios pertencentes ao cluster 2 destacam-se na atividade de extração e beneficiamento primário de minérios, em sua maior parte para exportação, os quais são tidos como minérios de classe mundial pelo seu volume de reservas e qualidade do minério, como o ferro do município de Parauapebas (maior PIB do estado e maior arrecadação da CFEM), a bauxita em Paragominas, o cobre em Canaã dos Carajás e Marabá, e o alumínio em Barcarena.Também são os municípios que mais arrecadam o royalty da mineração, o CFEM. (Gráfico 4). 
Gráfico 4 - Arrecadação da CFEM de Minerais, Pará - 2012

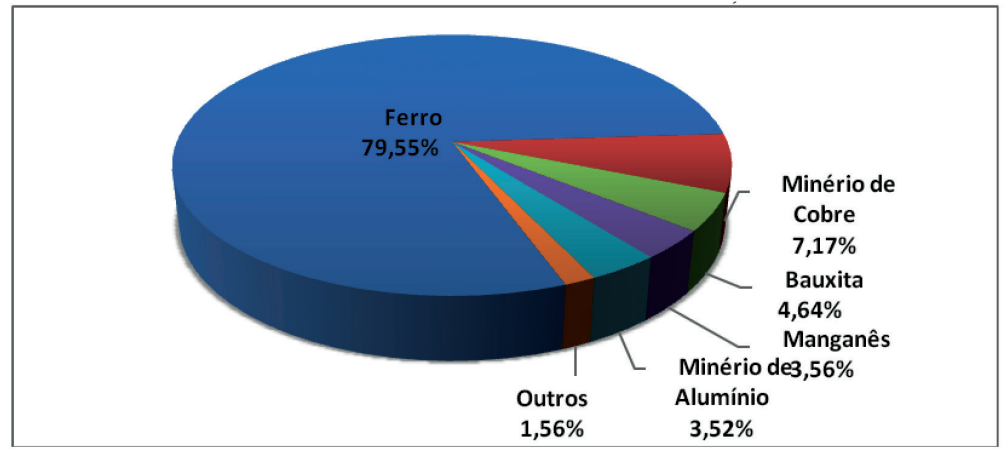

Fonte: DNPM (2010).

Ao mesmo tempo, entre os três agrupamentos, apresentam a mais alta arrecadação de ICMS, totalizando, em 2010, R \$ 337.527.283, quase oito vezes maior que a do cluster 1 e mais de 9 vezes superior a do cluster 3 .

Apesar da grande expressividade econômica, em termos de desmatamento, entre os três grupos, o cluster 2 não figura como maior explorador, ficando atrás do cluster 1 . Aliás, este cluster tem outras importantes atividades de maior destaque, como a madeireira e pecuária.

Além disso, o cluster 2 apresentou a maior quantidade de vínculos empregatícios em 2010, sendo 6 vezes maior que o cluster 1 e 5 vezes superior ao cluster 3 . Registrou, ainda, uma população quase 3 vezes maior que a de cada cluster.

O IFJAN do cluster 2 é 3.22 pontos maior que o do cluster 1 e 2.33 pontos acima do cluster 3 . No subíndice educação, o cluster 2 foi quase duas vezes maior que do cluster 1 , e 2 pontos maior que a do cluster 3 .

No IFJAN-Saúde, os subíndices não tiveram tantas disparidades, porém o cluster dois continua com índices mais elevados em consideração aos outros dois clusters.

Já o cluster 3 foi o que congregou municípios com menos especialização na atividade mineradora, destacando-se a agricultura e a pecuária extensiva, mas há grandes levas de capitais sendo investidos na autorização e pesquisa geológica e requisição de lavra. Além disso, está ocorrendo movimentação na retomada de projetos, como o de bauxita na região da Calha Norte, mais precisamente em Monte Alegre-Pará. 


\section{CONCLUSÕES}

O estado do Pará é importante explorador na atividade mineradora em relação ao resto do país e, em razão disso, tem contribuído sobremaneira para a formação do PIB, tanto estadual como nacional; de tal modo que, na pauta de exportação do estado, pelo menos os 5 principais itens de exportação são relativos aos produtos minerais.

Ademais, de 143 municípios existentes em 2010, 22,38\% possuem - em maior ou menor escala - a exploração de minérios, tendo como resultado um imposto importante (CFEM) que possa contribuir com outras atividades de infraestrutura em nível de estradas, saúde e educação. Aliás, foi verificado que o minério de ferro contribui com quase 80\%. Adicionalmente, dos 31 municípios que possuem esta atividade, respondem por $43 \%$ do PIB estadual e seu melhor desempenho está relacionado à saúde, cuja decomposição do IFIRJAN mostrouse mais elevado $(20,62)$, seguido da educação $(18,77)$ e emprego e renda, o menor índice $(14,91)$, o que vem confirmar estudos anteriores sobre o fraco encadeamento desta atividade com demais setores (à montante e à jusante) feito por Enriquez (1998). Para este autor, fazem-se necessárias mudanças na tributação, fiscalização e utilização dos royalties com a finalidade de tornar o setor mineral um genuíno vetor de desenvolvimento regional e de assegurar que as gerações presentes e futuras se beneficiem da exploração dos estoques minerais.

No que diz respeito aos clusters, estes foram determinados em número de três, denotando as similaridades maiores nos três índices decompostos do IFIRJAN (emprego e renda, educação e saúde). Destes, o mais importante em termos de geração de emprego foi o cluster 2, pois em termos econômicos e sociais foi o que apresentou maior número de empregos formais em 2010 e uma maior população; assim como o de educação, portanto, superior aos clusters 1 e 3, respectivamente, além de se registrar, apear das diferenças com relação ao item saúde, o cluster 2 ainda registrou maior coeficiente frente aos demais (redação confusa).

Por tudo isto, faz-se necessário o governo, seja este estadual ou federal, possuir maior contato com relação à exploração de minérios, via empresas que estão operando mais na região, para se ter retornos econômicos e sociais da atividade mineração para a sociedade local como um todo. No entanto, fazer isto exige maiores estudos e discussão sobre os retornos sociais desta atividade nos municípios mineradores paraenses. 


\section{REFERÊNCIAS}

BARCELLOS, E. A. de.; LIMA, M. H. R. Mineração e desflorestamento na Amazônia Legal. In: JORNADA DE INICIAÇÃO CIENTÍfICA, 10, 2002, Rio de Janeiro. Anais... Rio de Janeiro: CETEM/MCT, 2002. p. 56-66. Disponível em: <http://www.cetem.gov.br/jornadas/jornada-de-iniciacao-cientifica/ itemlist/category/35-2002>. Acesso em: 10 out. 2014.

BNDES - BANCO NACIONAL DE DESENVOLVIMENTO ECONÔMICO E SOCIAL. Panorama Mundial: O desempenho da economia mundial e perspectivas para os próximos anos. In: ALEM, A. C. et al. (Ed.). Sinopse Internacional. Rio de Janeiro, n. 12, set. 2009. p. 1 - 27.

CARVALHO, D. F. A indústria mineral não-metálica e seus índices de encadeamento produtivo na economia da região Norte: uma abordagem a partir das matrizes de insumo produto e de contabilidade social dos anos de 1985 e 1999. Amazônia: Ci. \& Desenv., Belém, v. 1, n. 2, p. 129-146, jan./jun. 2006.

The Amazon and the question in the context of globalization. In: SAHA, S. K.; PARKER, D. (Ed.). Globalization and sustainable development in Latin America: perspective on the new economic order. Cheltenham, UK: Edward Elgar, 2001.

CARVALHO, D. F; SANTANA, A. C.; MENDES, F. A. T. Análise de cluster da indústria de móveis de madeira do Pará. Novos Cadernos NAEA, Belém: vol. 9, n. 2, p. 25-53. dez. 2006

COSTA, J. M. M. da (Coord.). Os grandes projetos da Amazônia: impactos e perspectivas. Belém: UFPA/NAEA, 1987.

DEUS; L.A.B. de; NASCIMENTO, J. A. de. Desafio da sustentabilidade da mineração na Amazônia - o geoprocessamento como instrumento de análise. s/d. Disponível em: http://mineralis.cetem.gov.br/bitstream/cetem/882/1/ Leandroa.pdf. Acesso em: mar. 2017.

ENRIQUEZ, M. A. R. da S. Mineração e desenvolvimento sustentável - é possível conciliar? Revista de la Red Iberoamericana de Economía Ecológica, Quito - Ecuador, v. 1, n. 12, p. 51-66, 2009.

Royalties da mineração: instrumento de promoção do desenvolvimento sustentável de regiões mineradoras na Amazônia Oriental? Novos Cadernos NAEA, Belém, v. 1, n. 2, n.p. 1998. Disponível em: <http://www.periodicos. ufpa.br/index.php/ncn/article/view/15>. Acesso em: 29 out. 2012. 
FILGUERAS, G. C.; BENTES, E. dos S.; SANTOS, Z. J. C. G. dos. A degradação ambiental e produção agropecuária no estado do Pará: uma análise Multivariada. Cadernos CEPEC (Papers do PPGE), Belém, v. 2, n. 1, p. 1-25, jan. 2013.

HAIR JUNIOR, J. et al. Análise multivariada de dados. 5. ed. Porto Alegre: Bookman, 2006.

IBGE - INSTITUTO BRASILEIRO DE GEOGRAFIA E ESTATÍSTICA. Censo. Rio de Janeiro, 2010. Disponível em: <http://www.censo2010.ibge.gov. br/>. Acesso em: 10 nov. 2013.

Cidades. Rio de Janeiro, 2012. Disponível em: < http:/ /www.ibge.gov. $\mathrm{br} /$ cidadesat $/$ painel $/$ painel.php?codioumun $=290490>$.

Acessado em: 12 de nov. 2012 e 2013.

Cidades. Rio de Janeiro, 2013. Disponível em: < http:/ /www.ibge.gov. $\mathrm{br} / \mathrm{cidadesat} / \mathrm{painel} /$ painel.php?codioumun $=290490>$.

Acessado em: 12 dez. 2013

MDIC - MINISTÉRIO DO DESENVOLVIMENTO INDÚSTRIA E COMÉRCIO EXTERIOR. 2013. Documentos de exportação. Disponível em: <http://www.aprendendoaexportar.gov.br/sitio/paginas/comExportar/ docExportacao.html>. Acesso em: 05 nov. 2013.

Exportação por estado-aliceweb. 2012. Disponível em: <http:// www.desenvolvimento.gov.br/sitio/>. Acesso em: 04 set. 2013.

MINGOTI, S. A. Análise de dados através de métodos de estatística multivariada: uma abordagem aplicada. Belo Horizonte: UFMG, 2005.

MME - MINISTÉRIO DE MINAS E ENERGIA. Secretaria de Minas e Metalurgia. Perspectiva mineral, Brasília, n. 2, ago. 2009.

MONTEIRO, M. A. Meio século de mineração industrial na Amazônia e suas implicações para o desenvolvimento regional. Estudos Avançados, São Paulo, v. 19, n. 53, p. 187-207, 2005.

MONTEIRO, M. A.; BASTOS, A. P. V.; LIMA, M. A.; CORÔA FILHO, V. U.; COELHO, E. S. Formação de Aglomerações Empresariais e Limitações à Difusão Tecnológica: O Caso do Distrito Industrial de Barcarena, Pará. Revista Econômica do Nordeste, Fortaleza, v. 39, n. 2, p. 216-231, abr-jun. 2008.

OLIVEIRA, M. Amazônia e a Mineração. Amazônia real, n.p. 06 jun. 2016. Disponível em: <http://amazoniareal.com.br/amazonia-e-a-mineracao-2/>. Acesso em: 10 mar. 2017. 
RADETZKI, M. Economic growth and environment. In: LOW, P. (Ed.), International Trade \& the Environment. World Bank Discussion Papers, 159, 1992. The World Bank, Washington, DC.

RODRIGUEIS, A. C. M. Análise da eficiência socioeconômica dos municípios mineradores da Região Central de Minas Gerais. 2009. 123 f. Dissertação (Mestrado em Administração) - Universidade Federal de Viçosa. Viçosa-MG, 2009.

SIMINERAL - SINDICATO DAS INDÚSTRIAS MINERAIS DO ESTADO DO PARÁ. Anuário Mineral do Pará. 1 ed. Belém: Sindicato das Indústrias Minerais do Estado do Pará, 2013.

VIDAL, C; SANTANA, A. C. The role of the mineral sector in the development of the Amazon region. Belém: IMAZON, 1998 (Documento interno, 15 p.)

VIEIRA, E. A. A (in) sustentabilidade da indústria da mineração no Brasil. Estação Científica (UNIFAP). Macapá, v. 1, n. 2, p. 01-15, 2011. 15p. 